\title{
FEATURE Challenges and opportunities in transdisciplinary science: The experience of next generation scientists in an agriculture and climate research collaboration
}

Andrea D. Basche, Gabrielle E. Roesch-McNally, Lindsay A. Pease, Christopher D. Eidson, Guy Bou Lahdou, Mike W. Dunbar, Trevor J. Frank, Laura Frescoln, Lei Gu, Ryan Nagelkirk, Jose Pantoja, and Adam K. Wilke

\section{TRANSDISCIPLINARY SCIENCE}

Agriculture in the twenty-first century faces unprecedented challenges from increasing climate variability to growing demands on natural resources to globalizing economic markets. These emerging agricultural issues, spanning both human and natural dimensions, are uniquely formulated, exceedingly complex, and difficult to address within existing disciplinary domains (Eigenbrode et al. 2007; Reganold et al. 2011; Foley et al. 2005; Hansen et al. 2013). Therefore, the next generation of scientists working on these issues must not only be highly trained within a disciplinary context but must also have the capacity to collaborate with others to solve systems-level problems.

To this end, transdisciplinary research continues to grow in the agricultural context. Scientists are encouraged to bridge the social and biophysical sciences in addressing concurrent goals of maintaining high yielding commodities, productive ecosystem services,

Andrea D. Basche is a graduate research assistant in the Department of Agronomy, lowa State University, Ames, lowa. Gabrielle E. Roesch-McNally is a graduate research assistant in the Sociology Department, lowa State University, Ames, lowa. Lindsay A. Pease is a graduate research assistant in the Department of Food, Agricultural, and Biological Engineering at The Ohio State University, Columbus, Ohio. Christopher D. Eidson is a graduate research assistant in the Carbon Management and Sequestration Center at The Ohio State University, Columbus, Ohio. Guy Bou Lahdou is a design engineer at Irrigation Consulting Inc., Pepperell, Massachusetts. Mike W. Dunbar is a graduate research assistant in the Department of Entomology at lowa State University, Ames, lowa. Trevor J. Frank is a graduate research assistant in the Department of Agronomy at Purdue University, West Lafayette, Indiana. Laura Frescoln is a graduate research assistant in the Department of Agricultural Education and Studies, Ames, lowa. Lei $\mathrm{Gu}$ is a graduate research assistant in the Department of Biological Systems Engineering at the University of Wisconsin, Madison, Wisconsin. Ryan Nagelkirk is a graduate research assistant in the Department of Geological Sciences at Michigan State University, East Lansing, Michigan. Jose Pantoja is a PROMETEO Scientist in the Department of Life Sciences and Agriculture, Universidad de las Fuerzas Armadas, Sangolquí, Ecuador. Adam K. Wilke is a graduate research assistant in the Department of Sociology at lowa State University, Ames, lowa. and human well-being. This new scientific paradigm is what Collins et al. define as a "knowledge base that can be used to help solve current and future environmental challenges" (2011). Fry (2001) defines transdisciplinary studies as those that reach "a high degree of integration where theories, models and methods merge" across fields. Our conceptualization of transdisciplinarity is the integration of methods, information, and perspectives from several disciplines (Francis et al. 2008) as well as across academic and nonacademic stakeholders (Fry 2001).

We are on the frontier of a transformative era of new science, based on a changing scientific landscape that will demand greater transdisciplinary efforts and team science. As graduate students and junior scholars, we reflect as a cohort on our experiences as part of a large-scale collaborative scientific endeavor. Our perspectives and technical skills are being framed by this new scientific paradigm and will guide our individual and collective contributions to the scientific community as we move forward in our careers. This essay addresses the experience of the graduate students who are working in a unique and transformative transdisciplinary environment. Our goal is to offer examples of successful collaboration, challenges encountered, and opportunities for continued success to future practitioners of team science addressing complex social and ecological challenges.

\section{A COLLABORATIVE PROJECT}

The Climate and Corn-based Cropping Systems Coordinated Agricultural Project (Sustainable Corn CAP) is a collaboration of 11 midwestern institutions spanning 9 states. Funded by the USDA's National Institute for Food and Agriculture (USDA NIFA) in 2011 for a five-year duration, the Sustainable Corn CAP's objective is to create a functional network of scientists, educators, and extension professionals that facilitate collaborative research and education that focus on mitigating the effects of climate variability on cropping systems in the Midwest. The team is composed of more than 150 members, including 50 principal investigators, more than 40 graduate students, and various staff and technicians. Scientific disciplines within the project range from, but are not limited to, sociology, agricultural education, economics, climate science, entomology, plant pathology, soil science, agricultural systems engineering, agronomy, and weed science. Therefore, students are a part of a natural experiment-a practical exercise in new research territory - in how the next generation of scientists will be trained and maneuver in a transdisciplinary environment.

Describing advantages of the large-scale project, Mary Ann Rozum, USDA NIFA project representative and national program leader, said,

At USDA, one of our top priorities is sustaining food production in the future. That includes offering improved, more standardized geographic recommendations for farmers on climate change. If we had 20 smaller projects doing their own protocol, it would be far more difficult to compare results. With a large project we can really bracket the climate across the Corn Belt and compare the research. Can you anticipate particular disease problems in warmer or wetter areas? How do we project best management practices across the region? This is new territory for us, but a large project also offers smoother integration of research, extension, and teaching to allow for quicker information dissemination to farmers.

A major directive from the project's leadership team has been to encourage every team member to take part in activities that put transdisciplinary science into action, such as presenting research and attending integrated meetings. Below, former and current Sustainable Corn CAP students comment on ways that transdisciplinary activities provide the fundamental groundwork for collaboration (figure 1).

Lindsay Pease, a $\mathrm{PhD}$ candidate in agricultural engineering at Ohio State University, said,

The field research team has subdivided into smaller working groups based on 


\section{Figure 1}

Entomology graduate student Mike Dunbar (right), agronomy graduate student Andrea Basche (center), and agricultural education graduate student Laura Frescoln (left) participate in a demonstration of climate support tools for producers at the 2014 annual conference. In a voluntary survey of the team at the beginning of the project, all graduate students responded that they valued transdisciplinary collaboration while three-quarters responded that they were pleased with their efforts to engage in transdisciplinary research. Photo credit: Lois Wright Morton.

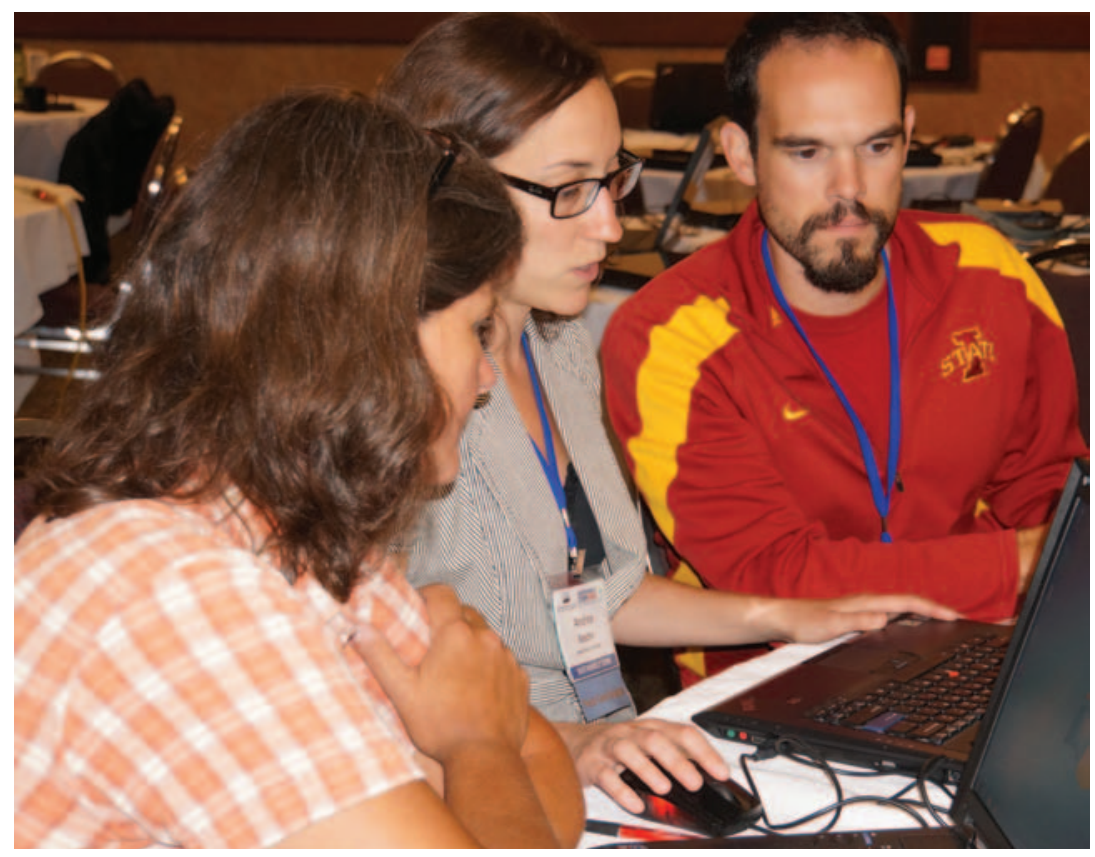

subject area, and I am a part of the drainage water management working group. These working groups facilitate collective brainstorming, a valuable skill to develop as a young scientist, by bringing together researchers from different universities and fields of study who are researching the same topic with regular conference calls. The groups also allow students to participate as equals with established faculty members and have solidified the importance of cooperation and sharing of information on transdisciplinary projects.

Trevor Frank, master's student in agronomy at Purdue University, noted,

As a new graduate student to the project, I found the annual meeting critical to understanding the 'big picture.' Since researchers normally only meet via conference calls, the annual meeting provided face-to-face interaction and the realization of how much contribution each person puts into the project.Various activities at the conference, such as graduate student poster sessions, table discussions, and social

\section{PROJECT CHALLENGES AND FUTURE RECOMMENDATIONS}

Despite the emphasis placed on the academic integration to address complex social ecological problems (National Academy of Science 2009), a number of challenges associated with the transition to transdisciplinary work remain. We define two major categories of challenges experienced by Sustainable Corn CAP students and propose recommendations for projects in the hope of achieving an improved working model of transdisciplinary team science.

Challenge: Breaking the Mold as Collaborative Pioneers. Although in recent years national funding agencies such as the National Science Foundation and USDA NIFA have moved toward promoting transdisciplinary projects, as pioneering students we observe that the general academic structure does not provide any clear pathways toward integration. Whitmer et al. (2010) similarly recognize both individual and disciplinary obstacles around this type of "engaged" research. On an individual level they note a lack of successful academic models participating in such research. At the disciplinary level, transdisciplinary science requires more time to produce outputs (e.g., multiauthored publications). This is problematic within the current academic framework because incentives for tenure and promotion traditionally place higher emphasis on disciplinary success (Daily and Ehrlich 1999; Goring et al. 2014). Numerous graduate students on our project have established productive research collaborations in spite of such obstacles. One exciting example is the pairing of landscape model scenarios with socioeconomic data, informed by farmer surveys and interview data that explore farmers' adaptive management responses to climate change. This will allow for more realistic predictions of how individual farmer decisions impact regional outcomes, such as water quality and greenhouse gas emissions.

Challenge: Heterogeneity in Student Experiences. Students in the Sustainable Corn CAP come from different disciplines with diverse disciplinary norms concerning methodology as well varying experiences based on length of time on the project (e.g., master's versus doctoral 
students) and attend universities in nine different states. Students are also tasked with varied requirements and coursework necessary to hone their specific disciplinary skills and methods. As a result, the path to engage in transdisciplinary research is nonlinear and varies from student to student. Thus, projects with transdisciplinary goals must harness that heterogeneity in a positive way to accomplish something that a single discipline could not achieve. The challenge is to offer systematic opportunities for students to experience the breadth of the project while not compromising individual students' institutional requirements. As a cohort, we developed a "roadmap" for project engagement (http:// sustainablecorn.org/About-People/ Graduate_Student_Roadmap.pdf) as a vessel to highlight such opportunities.

Recommendation: Define Appropriate Transdisciplinary Training for All Team Members. Principal investigators who serve as advisors to students typically have been trained in a disciplinary subject area. Thus, many of these principal investigators may lack successful models that could fully empower their students to gain experience and training as a transdisciplinary researcher. An explicit recommendation from our experience is that everyone involved-faculty, graduate students, team leadership, and funders - participate in an intentional transdisciplinary training program as part of participation in the project. The outline of a training program should ideally be incorporated from a project's inception. We suggest that this training have broad buy-in from all members of the team but still be flexible enough to accommodate various needs of all mentors and students. A training module should recognize that team science requires different skills than those that most faculty and graduate students generally have the opportunity to acquire. The suggested skills we propose to improve team science collaboration include project management, leadership, interpersonal dynamics, and communication (table 1). Wide participation will help cultivate a culture of successful collaboration and the skills required for team science, therefore hopefully reducing some of the heterogeneity experienced by students. We believe that if academia and the institutions that fund our work are truly

\section{Table 1}

Outline of suggested skills for transdisciplinary training.

\begin{tabular}{ll}
\hline Training component & $\begin{array}{l}\text { Beneficial skills and product outputs for members of Sustainable } \\
\text { Corn CAP transdisciplinary team }\end{array}$ \\
\hline Scientific training & $\begin{array}{l}\text { Disciplinary development (e.g., expert knowledge in research area) } \\
\text { Clear training in disciplinary requirements }\end{array}$ \\
Team dynamics & $\begin{array}{l}\text { Understanding multiple disciplinary frameworks and norms } \\
\text { Mutual respect and openness to different disciplinary approaches to } \\
\text { scientific questions }\end{array}$ \\
& Facilitation of group process to develop tangible results (e.g., shared \\
analysis, synthesis, and findings) & Development of shared products to communicate results to stakeholder groups \\
Communication & (e.g., research videos, extension publications, and/or education modules) \\
Leadership and & Leadership skill-building opportunities \\
project management & Project management skills to organize group process and development \\
& of outcomes \\
Mentoring opportunities (e.g., undergraduate research opportunities)
\end{tabular}

\section{Figure 2}

Sociology graduate student Gabrielle Roesch-McNally (right) exhibits different weed species for a short video production activity at the 2013 annual meeting. Students have participated in activities attempting to work outside of traditional academic silos such as those geared toward communicating science to external audiences. Photo credit: Lois Wright Morton.

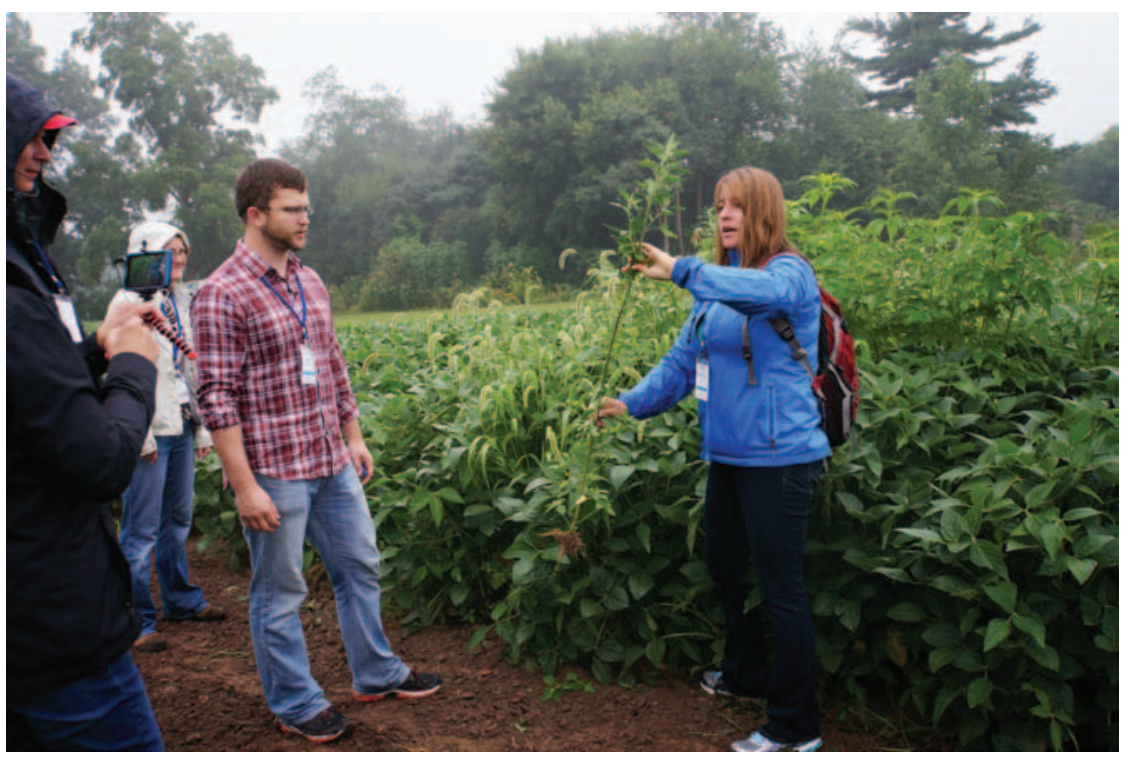

committed to creating a science that solves complex challenges, it will be necessary for such projects to intentionally address additional skills requirements (figure 2).

Recommendation: Create Networks for Communities of Practice. In order to provide more models of successful team collaborations and evolve social norms regarding academic research, we propose that projects explicitly include outside partnerships that can connect students and mentors to transdisciplinary science per the recommen- dations of Graybill et. al (2006). Romolini et al. (2013) emphasize the need to connect scientists, particularly graduate students, with a strong network in order to better integrate students into the bridge building process between the social and ecological sciences. Whitmer et al. (2010) also suggest that universities hire "professors of practice" from government and industry to help mentor students. The Sustainable Corn CAP continues to work on cultivating such a network through regular communications with our 


\section{Figure 3}

Sociology graduate student Adam Wilke (left) works with extension coordinator Jamie Benning (right) to present research on climate change communication for a group of Climate and Corn-based Cropping Systems Coordinated Agricultural Project scientists and staff at the 2013 annual conference. Project leadership encouraged graduate students to deliver both oral and poster presentations during regular meetings. Photo credit: Lois Wright Morton.

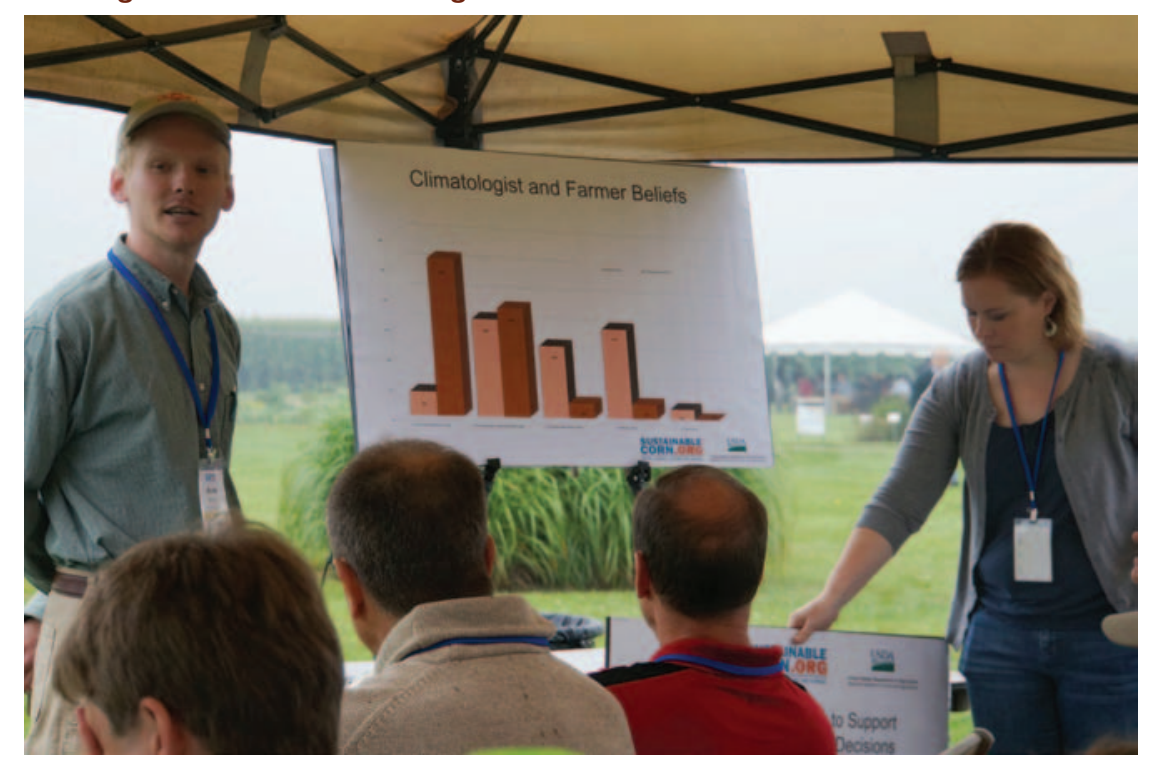

advisory board, a team of public, private, and nongovernmental organization partners. The education and leadership team, with input from graduate students, facilitated a series of webinars with practitioners from our advisory board to describe their work and as well as the skills needed for the next generation of scientists. We are also in the process of planning a career development retreat to further include input from our advisory board members. A more integrated network between graduate students and nonacademic mentors should be intentionally facilitated in order to share resources, information, and experiences of using science to solve real world problems. This type of network could also help to overcome some of the institutional bias that does not always reward this new paradigm of science (figure 3).

\section{CONCLUSION}

It is our goal to inform transdisciplinary collaborations by sharing the successes and challenges we have encountered as well as propose recommendations for future projects. We have observed that participants in team science require new skills and purposeful opportunities to learn that are not generally provided in the current academic setting. We recommend that transdisciplinary
Daily, G.C., and P.R. Ehrlich. 1999. Managing earth's ecosystems: An interdisciplinary challenge. Ecosystems 2(4):277-280.

Eigenbrode, S.D., M. O'Rourke, J.D. Wulfhorst , D.M. Althoff, C.S. Goldberg, K. Merrill, W. Morse, M. Nielsenpincus, J. Stephens, L. Winowiecki, and N.A. Bosque-Pérez. 2007. Employing philosophical dialogue in collaborative science. BioScience 57(1):55-64.

Foley, J.A., R. DeFries, G.P. Asner, C. Barford, G. Bonan, S.R. Carpenter, F. Stuart Chapin, M.T. Coe, G.C. Daily, H.K. Gibbs, J.H. Helkowski, T. Holloway, E.A. Howard, C.J. Kucharik, C. Monfreda, J.A. Patz, I.C. Prentice, N. Ramankutty, and P.K. Snyder. 2005. Global consequences of land use. Science 309:570-574.

Francis, C.A., G. Lieblein, T.A. Breland, L. Salomonsson, U. Geber, N. Sriskandarajah, and V. Langer. 2008. Transdisciplinary research for a sustainable agriculture and food sector. Agronomy Journal 100(3):771-776.

Fry, G. 2001. Multifunctional landscapes-towards transdisciplinary research. Landscape and Urban Planning 57:159-168

Goring, S.J., K.C. Weather, W.K. Dodds, P.A. Soranno, L.C. Sweet, K.S. Cheruvelil, J.S. Kominoski, J. Ruegg, A.M. Thorn, and R.M. Utz. 2014. Improving the culture of interdisciplinary collaboration in ecology by expanding measures of success. Frontiers in Ecology and the Environment 12(1):39-47.

Graybill, J.K., S. Dooling, V. Shandas, J. Withey, A. Greve, and G.L. Simon. 2006. A rough guide to Interdisciplinarity: Graduate student perspectives. BioScience. 56(9):757-763.

Hansen, J., P. Kharecha, M. Sato,V. Masson-Delmotte, F. Ackerman, D.J. Beerling, P.J. Hearty, O. HoeghGuldberg, S.L. Hsu, C. Parmesan, J. Rockstrom, E.J. Rohling, J. Sachs, P. Smith, K. Steffen, L. Van Susteren, K. Von Schuckmann, and J.C. Zachos. 2013. Assessing "Dangerous Climate Change:" Required reduction of carbon emissions to protect young people, future generations and nature. PLOS ONE 8(12):e81648

National Academy of Science. 2009. A new biology for the 21st century. Washington, DC: National Academies Press.

\section{ACKNOWLEDGEMENTS}

The team members involved in this research are part of a regional collaborative project supported by the USDANIFA, Award No. 2011-68002-30190, Cropping Systems Coordinated Agricultural Project: Climate Change, Mitigation, and Adaptation in Corn-based Cropping Systems. Project Web site: sustainablecorn.org.

\section{REFERENCES}

Collins, S.L., S.R. Carpenter, S.M. Swinton, D.E. Orenstein, D.L. Childers, T.L. Gragson, N.B. Grimm, J.M. Grove, S.L. Harlan, J.P. Kaye, A.K. Knapp, G.P. Kofinas, J.J. Magnuson, W.H McDowell, J.M. Melack, L.A. Ogden, G.P. Robertson, M.D. Smith, and A.C. Whitmer. 2011. An integrated conceptual framework for long-term social-ecological research. Frontiers in Ecology and the Environment 9(6):351-357.
Reganold, J.P., D. Jackson-Smith, S.S. Batie, R.R. Harwood, J.L. Kornegay, D. Bucks, C. B. Flora, J.C. Hanson, W.A. Jury, D. Meyer, A. Schumacher Jr., H. Sehmsdorf, C. Shennan, L.A. Thrupp, and P. Willis. 2011. Transforming US agriculture. Science 332(6030):670-671.

Romolini, M., S. Record, R. Garvoille,Y. Marusenko, and R.S. Geiger. 2013. The next generation of scientists: Examining the experiences of graduate students in network-level social-ecological science. Ecology and Society 18(3):42.

Whitmer, A., L. Ogden, J. Lawton, P. Sturner, P.M. Groffman, L. Schneider, D. Hart, B. Halpern, W. Schlesinger, S. Raciti, N. Bettez, S. Ortega, L. Rustad, S.T.A. Pickett, and M. Killilea. 2010. The engaged university: Providing a platform for research that transforms society. Frontiers in Ecology and the Environment 8(6):314-321. 